\title{
It is time for certification in cardiothoracic critical care
}

\author{
Nevin M. Katz, MD
}

In June of 2008, the American Board of Thoracic Surgery (ABTS) convened a special committee to consider certification in cardiothoracic critical care. The committee included ABTS chair Richard H. Feins, Thoracic Surgery Directors Association president John H. Calhoun, William A. Baumgartner, David A. Fullerton, William A. Gay, Jr, George L. Hicks, Jr, Valerie W. Rusch, and Curtis G. Tribble, all leaders in thoracic surgery education. As one of the thoracic surgeons who had emphasized that cardiothoracic critical care was a unique specialty and that cardiothoracic surgeons had a leadership role in the specialty, ${ }^{1}$ I was invited to participate in the meeting. The consensus of the meeting, after reviewing the situation in specialty board certification, was that the time was not right to move ahead with certification of cardiothoracic critical care by the ABTS. With the emphasis on cardiothoracic critical care since that time within the specialty of thoracic surgery, however, I now believe that the groundwork has been accomplished for the ABTS to proceed with creating its own pathways to certification in cardiothoracic critical care.

At the meeting in 2008, the committee recognized that critical care is a core component of Thoracic Surgery. The ABTS specifically has written, "Thoracic Surgery encompasses the operative, perioperative, and surgical critical care of patients with acquired and congenital pathologic conditions within the chest." 2 Although it was recognized that a good case could be made for proceeding with the certification at that time, there was concern that other specialty boards might criticize and potentially block the process because thoracic surgery did not then have extensive credibility in critical care education. Residency programs were recognized to be relatively weak in this area, and there was only a single annual cardiothoracic critical care continuing medical education course, the Foundation for the Advancement of CardioThoracic Surgical Care (FACTS-Care) course "Cardiothoracic Surgical Critical Care" created in 2004. Although that course was created by a thoracic surgeon and thoracic surgeons made up the majority of the faculty, it was believed that overall thoracic

From the Division of Cardiac Surgery, Johns Hopkins University, Baltimore, Md; and the Foundation for the Advancement of Cardiothoracic Surgical Care, Washington, DC.

Disclosures: Author has nothing to disclose with regard to commercial support.

Received for publication Jan 3, 2013; accepted for publication Jan 28, 2013; available ahead of print Feb 22, 2013.

Address for reprints: Nevin M. Katz, MD, Johns Hopkins Hospital, 1800 Orleans St, Suite 7107, Baltimore, MD 21287-4618 (E-mail: NevinKatz@aol.com).

J Thorac Cardiovasc Surg 2013;145:1446-7

$0022-5223 / \$ 36.00$

Copyright (c) 2013 by The American Association for Thoracic Surgery

http://dx.doi.org/10.1016/j.jtcvs.2013.01.045 surgery did not have sufficient credibility for the ABTS to create a certification in cardiothoracic critical care.

Since that time, there have been a remarkable number of educational developments. The ABTS has enlarged its curriculum for training in critical care and the critical care content of examinations has been expanded. Fellowships in cardiothoracic critical care have been created. The annual FACTS-Care course, which changed its title to "Cardiovascular-Thoracic (CVT) Critical Care" to recognize the merging of the fields of cardiovascular surgery and interventional cardiology, continues to update surgeons and their critical care teams. In addition, there are now cardiothoracic critical care postgraduate courses at both the American Association for Thoracic Surgery (AATS) and Society of Thoracic Surgeons (STS) annual meetings. Breakout sessions in mechanical assist, extracorporeal membrane oxygenation, and bedside ultrasonography are regular components of the AATS, STS, and FACTS-Care courses, and case scenario hemodynamic simulations are now part of the AATS and FACTS-Care courses. All this is a reflection of the work by leaders from both the AATS and STS.

Articles regarding the importance of thoracic surgeons performing critical care and providing educational resources have been published..$^{3-7}$ In the last year The Journal of Thoracic and Cardiovascular Surgery, led by its Editor Lawrence Cohn, has created an associate editorship in perioperative management. Overall, thoracic surgery has created the educational platform that was envisioned at the 2008 meeting.

Currently, it can be difficult for thoracic surgeons to practice cardiothoracic critical care in their intensive care units, both for their patients and those of other thoracic surgeons. Hospitals in this era are driven to require intensivists to be certified by the American Board of Internal Medicine, the American Board of Anesthesiology, or the American Board of Surgery. Remarkably, although these boards represent expertise in the broad field of critical care, they do not provide the depth of understanding and knowledge that is unique to the specialty of cardiothoracic critical care.

Thoracic surgeons recognize the advantages of having non-thoracic surgeon intensivists on the cardiothoracic critical care team, as they have special areas of expertise. Thoracic surgeons also recognize, however, that it is the cardiothoracic surgeon who best understands the unique physiologies of cardiopulmonary bypass and cardiovascular, pulmonary, esophageal, and chest wall surgery, as well as the unique associated complications. Thoracic surgeons also perform procedures unique to cardiothoracic critical care, such as insertion and removal of intra-aortic balloon pumps and other support devices. Accordingly, it 
is highly appropriate for the thoracic surgeon to have a leadership role on the multidisciplinary cardiothoracic critical care team. Remarkably, cardiothoracic surgeons find that they cannot provide credentialing to hospitals to perform cardiothoracic critical care, despite in many cases thousands of hours of experience in the specialty. The ABTS administration has responded to requests to provide verification to hospitals that cardiothoracic critical care is a core component of thoracic surgery.

Recognizing the potential political obstacles faced by the ABTS in creating its own certification in cardiothoracic critical care, leaders of the ABTS have worked diligently with the American College of Surgery to create a pathway for thoracic surgeons to achieve critical care certification. William Baumgartner and Valerie Rusch are to be commended for their efforts in this regard. They have paved the way for cardiothoracic fellowships and for certification. Fellowships have been created on the basis of their work. Ultimately, however, more pathways are needed for surgeons already in practice, and for residents who desire to apply their surgical training immediately after completing their cardiothoracic residency.

In setting up criteria for certification, it is important that surgeons currently in practice do not become disenfranchised from performing critical care for their patients and those of their colleagues. It is important that surgeons continue to be updated in the latest concepts and management methods and protocols. It should be possible for any ABTScertified thoracic surgeon to practice cardiothoracic critical care and to be certified in cardiothoracic critical care through a combination of experience, continuing medical education courses, and examinations.

A formal process of ABTS certification in cardiothoracic critical care, with several pathways, can now be defined. Certification can be based on a variety of criteria: formal training, such as in cardiothoracic residencies and fellowships; documented clinical experience; participation in continuing medical educational programs; completion of
Self-Education Self Assessment in Thoracic Surgery; and ABTS examinations.

Cardiothoracic surgeons recognize that their colleagues in cardiothoracic anesthesiology are in a position to share the surgeon's unique understanding of cardiothoracic operations, the associated physiologic changes, and the potential complications. In many centers, cardiovascular or cardiothoracic anesthesiologists have an important role on the multidisciplinary team in the cardiothoracic intensive care unit. It therefore seems appropriate, as the ABTS develops its approach to certification in cardiothoracic critical care for thoracic surgeons, that consideration be given to inclusion of our colleagues in anesthesiology.

Overall then, I believe that the ABTS, working with leaders of the AATS and STS, is now in a position to create certification in cardiothoracic critical care. It will be important to address the need for several pathways for thoracic surgeons at various stages of their careers. Once this certification is in place, thoracic surgeons will be able to point out to hospitals that, just as the ABTS certifies thoracic surgeons to perform cardiac and thoracic operations, the ABTS certifies thoracic surgeons to perform cardiothoracic critical care, which is a core component of the specialty.

\section{References}

1. Katz NM. The emerging specialty of cardiothoracic surgical critical care: the leadership role of cardiothoracic surgeons on the multidisciplinary team. $J$ Thorac Cardiovasc Surg. 2007;134:1109-11.

2. The American Board of Thoracic Surgery. Booklet of information. Chicago: The Board; 2012.

3. Stamou SC, Camp SL, Stiegel RM, Reames MK, Skipper E, Watts LT, et al. Quality improvement program decreases mortality after cardiac surgery. J Thorac Cardiovasc. Surg. 2008;136:494-9.

4. Kumar K, Zarychanski R, Bell DD, Manji R, Zivot J, Menkis AH, et al. Impact of 24-hour in-house intensivists on a dedicated cardiac surgery intensive care unit. Ann Thorac Surg. 2009;88:1153-61.

5. Katz NM. The evolution of cardiothoracic critical care. J Thorac Cardiovasc Surg. 2011;141:3-6.

6. Whitson BA, D'Cunha J. The thoracic surgical intensivist: the best critical care doctor for our thoracic surgical patients. Semin Thoracic Surg. 2011;23:12-3.

7. Sherif HM. Developing a curriculum for cardiothoracic surgical critical care: impetus and goals. J Thorac Cardiovasc Surg. 2012;143:804-8. 